\title{
Habitual meal frequency in relation to resting and activity-induced energy expenditure in human subjects: the role of fat-free mass
}

Citation for published version (APA):

Westerterp-Plantenga, M. S., Goris, A. H. C., Meijer, E. P., \& Westerterp, K. R. (2003). Habitual meal frequency in relation to resting and activity-induced energy expenditure in human subjects: the role of fatfree mass. British Journal of Nutrition, 90(3), 643-649. https://doi.org/10.1079/BJN2003940

Document status and date:

Published: 01/01/2003

DOI:

10.1079/BJN2003940

Document Version:

Publisher's PDF, also known as Version of record

Document license:

Taverne

Please check the document version of this publication:

- A submitted manuscript is the version of the article upon submission and before peer-review. There can be important differences between the submitted version and the official published version of record.

People interested in the research are advised to contact the author for the final version of the publication, or visit the DOI to the publisher's website.

- The final author version and the galley proof are versions of the publication after peer review.

- The final published version features the final layout of the paper including the volume, issue and page numbers.

Link to publication

\footnotetext{
General rights rights.

- You may freely distribute the URL identifying the publication in the public portal. please follow below link for the End User Agreement:

www.umlib.nl/taverne-license

Take down policy

If you believe that this document breaches copyright please contact us at:

repository@maastrichtuniversity.nl

providing details and we will investigate your claim.
}

Copyright and moral rights for the publications made accessible in the public portal are retained by the authors and/or other copyright owners and it is a condition of accessing publications that users recognise and abide by the legal requirements associated with these

- Users may download and print one copy of any publication from the public portal for the purpose of private study or research.

- You may not further distribute the material or use it for any profit-making activity or commercial gain

If the publication is distributed under the terms of Article $25 \mathrm{fa}$ of the Dutch Copyright Act, indicated by the "Taverne" license above, 


\title{
Habitual meal frequency in relation to resting and activity-induced energy expenditure in human subjects: the role of fat-free mass
}

\author{
Margriet S. Westerterp-Plantenga*, Annelies H. C. Goris, Erwin P. Meijer and \\ Klaas R. Westerterp \\ Department of Human Biology, University of Maastricht, Maastricht, The Netherlands
}

(Received 2 January 2003 - Revised 10 April 2003 - Accepted 13 May 2003)

\begin{abstract}
Habitual meal frequency was assessed as a possible function of components of energy expenditure (EE) in human subjects. Fifty-six subjects participated (four categories differing in body composition): ten older women (fat-free mass (FFM) 42.0 (SD 6.3) kg, aged 59 (SD 2) years, BMI 27.5 (SD 6.9) kg/m²), fifteen younger women (FFM 45.5 (SD 5.2) kg, aged 34 (SD 10) years, BMI 21.9 (SD 2.3) kg/m²), twelve older men (FFM 56.8 (SD 5.9) kg, aged 62 (SD 4) years, BMI $25.7(\mathrm{SD} 3.3) \mathrm{kg} / \mathrm{m}^{2}$ ) and nineteen younger men (FFM 63.9 (SD 7.5) kg, aged 23.1 (SD 3.9) years, BMI $\left.22.9(\mathrm{SD} 1.8) \mathrm{kg} / \mathrm{m}^{2}\right)$. Measurements consisted of habitual meal frequency by validated food-intake diaries, physical activity by tri-axial accelerometers and resting EE by a ventilated hood system. Habitual meal frequency was expressed as a function of resting EE (including resting $\mathrm{EE}$ as a function of FFM), and of activity-induced EE, using regression analysis. FFM differed according to gender and age categories $(P<0 \cdot 01)$. Physical activity level was higher in the younger men than in the other categories $(P<0 \cdot 05)$. No relationship of meal frequency with the variables assessed was observed in subjects with a low FFM (the women). In the subjects with a medium FFM (the older men), meal frequency was positively related to resting $\operatorname{EE}\left(r^{2} 0 \cdot 4, P<0 \cdot 05\right)$, but not to the residuals of resting EE as a function of FFM, and inversely related to activity-induced EE $\left(r^{2} 0 \cdot 3, P<0 \cdot 05\right)$. Resting EE explained $40 \%$ of the variation in meal frequency; adding activity-induced EE increased this to $60 \%$. In the subjects with a high FFM (the younger men), meal frequency was inversely related to resting EE $\left(r^{2} 0 \cdot 8, P<0 \cdot 0001\right)$ and to the residuals of resting EE as a function of FFM $(P=0.03)$, and positively related to activity-induced EE $\left(r^{2} 0 \cdot 6, P<0 \cdot 0001\right)$. Resting EE explained $85 \%$ of the variation in meal frequency; adding activity-induced EE increased this to $89 \%$. Habitual meal frequency was a function of components of EE, namely resting EE and activity-induced EE, only in subjects with a medium to high FFM (men). FFM-related differences in these relationships suggest a role of physical activity.
\end{abstract}

Age: Body composition: Gender: Physical activity: Man

Previous studies assessing the role of habitual meal frequency in maintaining energy balance have focused on energy intake (EI) regulation, including macronutrient composition, as well as on energy expenditure (EE), but not including the components of EE separately. For instance, EI per d appeared to be regulated more accurately in nibblers than in meal feeders, and in high-carbohydrate consumers than in high-fat consumers (Westerterp-Plantenga et al. 1994, 2002). Accuracy of EI regulation is defined as the degree of compensation for interventions that might change EI, resulting in the same EI per $d$ as in the control situation. For instance, nibblers with their habitually higher meal frequency showed a similar EI per $\mathrm{d}$ on a day with an intervention, i.e. a reduced EI at lunchtime, as on the control day. In meal feeders this accuracy was not present, since their EI per $d$ on the intervention days remained reduced by the magnitude of the reduction in EI at lunchtime (Westerterp-Plantenga et al. 1994).
In accordance with this, Drummond et al. (1998) showed an inverse relationship between body-weight status and eating frequency in male, but not female, non-obese adults, reporting valid dietary intakes. Less frequent eaters tended to be overweight and more frequent eaters were of normal weight. Moreover, improved EI regulation was associated with an introduced increased frequency of eating in lean male subjects (Speechly \& Buffenstein, 1999), and acute EI reduction was associated with an introduced increased frequency of eating in obese male subjects (Speechly et al. 1999). The combination of these results suggests that improvements in EI regulation appear when EI is spread evenly over the course of a day, i.e. regulation of EI might be a function of meal frequency.

With respect to body-weight regulation, most epidemiological studies from the last three decades report an inverse relationship between body weight or BMI, or \% body fat, or waist: hip ratio in human subjects and meal frequency 
(Hejda \& Fabry, 1964; Fabry et al. 1964, 1966; Metzner et al. 1977; Charzewska et al. 1981; Edelstein et al. 1992; Speechly \& Buffenstein, 1999; Speechly et al. 1999). However, lack of such a relationship has also been reported (Dreon et al. 1988; Kant, 1995; Summerbell et al. 1996). Since these epidemiological studies obtained EI data from food intake diaries, which, if not validated, are subject to under-reporting (Bellisle et al. 1997; Goris \& Westerterp, 2000; Goris et al. 2000, 2001), those results may be disputable, in that it is not known how underreporting affects meal frequency. It may be hypothesized that apart from regulation of EI being a function of meal frequency, regulation of body weight may also be a function of meal frequency.

Recently, we reported from a controlled experimental study that in healthy young men accuracy of EI regulation was positively related to habitual meal frequency, and that EI was inversely related to habitual meal frequency (Westerterp-Plantenga et al. 2002). Accuracy of regulation was shown as the minimum or no difference between EI per $\mathrm{d}$ on days with an intervention in macronutrient composition, and EI per d on control days. Assessing the cause of habitual meal frequency, variation appeared to be partly explained by blood glucose patterns, and this was related to macronutrient composition (Westerterp-Plantenga et al. 2002). This relationship of a factor in EI, namely meal frequency, with a metabolic factor, namely blood-glucose patterns (consisting of transient blood glucose declines related to meal initiation and dynamic blood glucose declines related to intermeal interval (Westerterp-Plantenga et al. 2002)), indicates that habitual meal frequency might be physiologically linked to energy metabolism.

To be in energy balance, EI should be tuned to the energy requirement, i.e. EE. However, EI is only loosely coupled with EE, and this relationship is not significant when assessed per $\mathrm{d}$, but it is significant over 1 week (Westerterp \& Elbers, 1999; Westerterp \& Goran, 1999). EI is tuned to the energy requirement partly by hunger and satiety mechanisms, partly by cognitive factors (Melanson et al. 1999). Until now, no indications have been reported on components of EI being related to components of EE. From its role in determining EI, meal frequency might be a factor in this relationship. Existing results suggest that different meal frequencies do not change total EE per d (Dalosso et al. 1982; Wolfram et al. 1987; Verboeket-van de Venne \& Westerterp, 1991, Verboeket-van de Venne et al. 1993a,b). However, EE is only a function of EI to a small extent, namely with respect to diet-induced EE (Charzewska et al. 1981; Bellisle et al. 1997; Melanson et al. 1999; Westerterp \& Elbers, 1999; Westerterp-Plantenga et al. 1999, 2002), which might explain why total EE does not depend on meal frequency. On the other hand, EI is a function of EI (Charzewska et al. 1981; Bellisle et al. 1997; Melanson et al. 1999; Westerterp \& Elbers, 1999; Westerterp-Plantenga et al. 1999, 2002). Thus, habitual meal frequency may have a metabolic cause, since it changes with a metabolic factor, namely blood glucose patterns (Westerterp-Plantenga et al. 2002). The question thus remains whether different EE may give rise to different meal frequencies. The components of $\mathrm{EE}$ that we focused on are resting EE, the largest part of EE, i.e. 60-70\% (Westerterp \& Elbers, 1999) and activityinduced EE, the most variable part of EE (Westerterp \& Elbers, 1999). The main determinant of $\mathrm{EE}$ is fat-free mass (FFM), which is determined by age and gender, in that younger men have a relatively large FFM, followed by older men, then younger women, then older women (Westerterp \& Elbers, 1999; Westerterp \& Meijer, 2001). Thus, we assessed whether habitual meal frequency is a function of the components resting EE and activity-induced $\mathrm{EE}$ of $\mathrm{EE}$, in a population of subjects with a wide range in body composition. In order to acquire subjects with these characteristics, different categories with respect to FFM using age and gender were recruited.

\section{Methods}

\section{Subjects}

Subjects ( $n$ 80), men and women, aged $18-70$ years, were recruited through the University and local newspaper. They were selected on not having fixed time schedules during the week, which might affect meal patterns. The older subjects appeared to be retired; the younger subjects were students. They all gave written informed consent. BMI was determined as weight $(\mathrm{kg}) / \mathrm{height}(\mathrm{m})^{2}$, using a digital scale accurate to $0 \cdot 1 \mathrm{~kg}$ (type E1200; Sauter, Ebingen, Germany) and a wall-mounted stadiometer (model 220; Seca, Hamburg, Germany). Body composition was determined by ${ }^{2} \mathrm{H}$ dilution (Westerterp et al. 1995). For the data analysis, only the subjects who reported their food intake accurately (Goris et al. 2001) were included ( $n$ 56). To determine the degree of dietary restraint, the threefactor eating questionnaire (Stunkard \& Messick, 1985) was completed by the subjects. In order to discriminate between groups differing in body composition, subjects were divided into four groups, matched by age and gender; their characteristics are given in Table 1 . The cutoff point for age was 50 years, thus distinguishing between pre- and post-menopausal women. The groups had different sizes or age ranges because of the selection criteria: not having fixed time schedules during the week and reporting food intake accurately. The protocol was approved by the Medical Ethics Committee of the Academic Hospital of the University of Maastricht.

\section{Procedures}

Habitual meal frequency. Habitual meal frequency was calculated from the food intake diaries, which were completed by the subjects and validated for these subjects in the present study. Habitual food and water intake was recorded in a food intake diary for seven consecutive days. Subjects were instructed by a dietitian on how to complete a food intake diary accurately and correctly, and to pay special attention to recording each separate eating occasion, including the time. The food intake diaries were structured with a section for each hour. This way, subjects were kept aware every hour whether they had eaten something and they could make a note of it. The subjects were asked not to change their habitual food intakes. Validation of the EI reported in the food intake 
Table 1. Subject characteristics, energy expenditure, energy intake, macronutrient composition (\% energy from carbohydrate, protein and fat) and meal frequency, divided according to gender and age

(Mean values and standard deviations)

\begin{tabular}{|c|c|c|c|c|c|c|c|c|}
\hline & \multicolumn{4}{|c|}{ Female } & \multicolumn{4}{|c|}{ Male } \\
\hline & \multicolumn{2}{|c|}{ Older (n 10) } & \multicolumn{2}{|c|}{ Younger (n 15) } & \multicolumn{2}{|c|}{ Older (n 12) } & \multicolumn{2}{|c|}{ Younger (n 19) } \\
\hline & Mean & SD & Mean & SD & Mean & SD & Mean & SD \\
\hline Age (years)§ & $59 \cdot 4$ & 2.4 & $34 \cdot 7^{\star \star}$ & $6 \cdot 9$ & $61 \cdot 6$ & $4 \cdot 1$ & $23 \cdot 1^{\star \star}$ & 2.9 \\
\hline BMI $\left(\mathrm{kg} / \mathrm{m}^{2}\right)$ & $27 \cdot 5$ & 6.9 & $21 \cdot 9^{\star \star}$ & $2 \cdot 3$ & $25 \cdot 7$ & $3 \cdot 3$ & 22.9 & $1 \cdot 8$ \\
\hline Body mass (kg) & $67 \cdot 4 \dagger$ & $9 \cdot 2$ & $60 \cdot 4^{\star \star} \dagger$ & $7 \cdot 3$ & $78 \cdot 3$ & $8 \cdot 8$ & $75 \cdot 3$ & $10 \cdot 4$ \\
\hline Height (m) & $1.63 \dagger$ & 0.6 & $1.66 \dagger$ & 0.6 & 1.75 & 0.05 & $1 \cdot 80$ & 0.05 \\
\hline FM (\%) & $37 \cdot 7 \dagger$ & $4 \cdot 7$ & $24 \cdot 2^{\star \star} \dagger$ & $3 \cdot 8$ & $27 \cdot 5$ & $5 \cdot 7$ & $15 \cdot 2^{\star \star}$ & $3 \cdot 1$ \\
\hline FFM (kg) & $42.0 \dagger$ & $6 \cdot 3$ & $45.5 \dagger$ & $5 \cdot 2$ & $56 \cdot 8$ & 5.9 & $63 \cdot 9^{\star *}$ & 7.5 \\
\hline FFM index $\left(\mathrm{kg} / \mathrm{m}^{2}\right)$ & $15.8 \dagger$ & 4.5 & $16.5 \dagger$ & 1.9 & $18 \cdot 6$ & $3 \cdot 1$ & $19 \cdot 7$ & 3.0 \\
\hline Resting EE (MJ/d) & $5 \cdot 7 \dagger$ & 0.6 & $6.0 \dagger$ & 0.4 & $7 \cdot 2$ & 0.7 & $7 \cdot 7$ & 0.5 \\
\hline $\mathrm{RQ}$ & 0.86 & 0.02 & 0.87 & 0.02 & 0.84 & 0.01 & 0.85 & 0.02 \\
\hline $\mathrm{EE}(\mathrm{MJ} / \mathrm{d})$ & $9 \cdot 4 \dagger$ & 1.0 & $9 \cdot 4 \dagger$ & $1 \cdot 3$ & 11.9 & 0.9 & $13 \cdot 1$ & 0.9 \\
\hline Activity-induced EE & $3 \cdot 7 \dagger$ & $1 \cdot 1$ & $3.4 \dagger$ & 1.4 & 4.7 & $1 \cdot 2$ & 5.4 & $1 \cdot 6$ \\
\hline $\mathrm{PAL}$ & 1.65 & 0.3 & $1.56^{\star} \dagger$ & 0.3 & 1.65 & 0.3 & $1 \cdot 70^{*}$ & 0.4 \\
\hline Meal frequency $(n$ per $d) \|$ & $5 \cdot 3$ & 0.7 & $5 \cdot 7$ & 0.7 & $5 \cdot 2$ & 0.7 & $5 \cdot 7$ & $2 \cdot 0$ \\
\hline $\mathrm{El}(\mathrm{MJ} / \mathrm{d})$ & $9 \cdot 2 \dagger$ & $1 \cdot 3$ & $9 \cdot 1 \dagger$ & $1 \cdot 7$ & $11 \cdot 8$ & $1 \cdot 2$ & $13 \cdot 0$ & 1.5 \\
\hline \multicolumn{9}{|l|}{$\%$ Energy from: } \\
\hline Carbohydrate & 11 & 1 & 12 & 2 & 13 & 2 & 12 & 2 \\
\hline Protein & 53 & 5 & 55 & 7 & 49 & 6 & 52 & 7 \\
\hline Fat & 36 & 3 & 33 & 4 & 38 & 4 & 36 & 5 \\
\hline \multicolumn{9}{|l|}{ Attitude to eating } \\
\hline F1 (cognitive restraint) & $6 \cdot 3$ & 2.9 & $7 \cdot 1 \dagger$ & $2 \cdot 2$ & $5 \cdot 4$ & $2 \cdot 8$ & $4 \cdot 4$ & $3 \cdot 1$ \\
\hline F2 (disinhibition) & $5 \cdot 2$ & 2.7 & $6.4 \dagger$ & 3.7 & $4 \cdot 2$ & $2 \cdot 4$ & $3 \cdot 8$ & $2 \cdot 2$ \\
\hline F3 (general hunger) & $3 \cdot 1$ & 1.5 & $3 \cdot 2$ & $2 \cdot 3$ & $3 \cdot 3$ & $2 \cdot 1$ & $4 \cdot 2$ & 2.9 \\
\hline
\end{tabular}

FM, fat mass; FFM, fat-free mass; EE, energy expenditure; PAL, physical activity level; El, energy intake.

Mean values were significantly different from those of older subjects of the same gender: ${ }^{\star} P<0.05$, ${ }^{\star \star} P<0.01$.

Mean values were significantly different from those of male subjects in the same age group: $\dagger P<0 \cdot 01$.

$\ddagger$ For details of procedures, see p. 644.

$\S$ Ranges (years): older female 55-65, younger female $20-50$, older male 55-70, younger male 18-30.

$\|$ Ranges $(n$ per d): older female $4-7$, younger female $4-7$, older male $4-7$, younger male $2-8$.

ๆ Three-factor eating questionnaire; for details, see Stunkard \& Messick (1985).

diaries was executed using a comparison of reported EI with calculated $\mathrm{EE}$ on the basis of resting EE, measured with the ventilated hood technique, and physical activity, measured with a triaxial accelerometer (Goris et al. 2001). This method had been validated previously by measuring total EE by the doubly-labelled water method (Goris et al. 2001). Over 1 week, if body weight is stable, EI matches EE; therefore, validating reported EI with measured EE is a check for accuracy of EI reporting (Westerterp \& Elbers, 1999; Goris \& Westerterp, 2000; Goris et al. 2000, 2001). Subjects reporting within $\pm 10 \%$ accuracy based upon the validation for the present study were selected. Food intake diaries were analysed using the Dutch nutrient database (Stichting Nederlands Voedingsstoffen Bestand, 1993). Meal frequency was determined as the number of eating occasions during which energy-containing food is ingested, separated by at least $15 \mathrm{~min}$.

Resting energy expenditure, activity-induced energy expenditure and physical activity level. Resting EE was determined using a ventilated hood system and physical activity was determined using a validated tri-axial accelerometer (Goris et al. 2001). EE was calculated as follows (Goris et al. 2001):

$$
\begin{aligned}
\operatorname{EE}(\mathrm{MJ} / \mathrm{d})= & -1.259+1.55 \text { resting } \mathrm{EE}(\mathrm{MJ} / \mathrm{d}) \\
& +0.076 \text { counts }(n) / \mathrm{min} .
\end{aligned}
$$

Activity-induced EE was calculated as EE-resting EE. Physical activity level (PAL) was calculated as EE/ resting EE.

\section{Statistics}

Body composition was expressed as \% body fat (\% fat mass (FM)), FFM (kg) and as FFM index (FFM (kg)/ height $\left(\mathrm{m}^{2}\right)$ ). Possible differences between relevant subject characteristics between the gender and age categories were determined using the Mann-Whitney test. The same test was used to determine possible differences in meal frequency and in the range in meal frequency.

Possible relationships between meal frequency and other variables were determined by simple regression analysis. The possible relationship between meal frequency and resting EE, as well as activity-induced EE, was determined by stepwise regression analysis. The possible relationship between habitual meal frequency and the residuals of the regression analysis of resting EE expressed as a function of FFM was determined by simple regression analysis. This was executed to analyse whether a possible relationship of meal frequency with resting EE was in fact a relationship with FFM.

The computer software program Statview 2.0 (Statview \& Graphics; Abacus Concepts Inc., Berkeley, CA, USA) for Macintosh was used and statistical significance was accepted as $P<0 \cdot 05$. 


\section{Results}

\section{Energy balance}

The weights of the subjects were stable over the experimental weeks, indicating that they were in energy balance and that energy requirements were met.

\section{Habitual meal frequency}

Habitual meal frequencies from the food intake diaries ranged from two to eight eating occasions per d (Table 1). In general, these were quite formal eating occasions. Two eating occasions consisted of lunch and dinner and three eating occasions of breakfast, lunch and dinner. With four to eight eating occasions per $\mathrm{d}$, a coffee break in the morning, a tea break in the afternoon, a snack before dinner, a coffee break after washing-up and a drink with a snack later in the evening were added at most.

\section{Body composition, gender and age}

Body composition was significantly different between the four categories of subjects (Table 1). Moreover, the younger women differed significantly from the older women with respect to BMI, body mass, \% FM, age $(P<0.01)$ and PAL $(P<0.05)$ (Table 1). The younger men differed significantly from the older men in body composition $(\%$ FM and FFM), age $(P<0 \cdot 01)$ and PAL $(P<0.05)$ (Table 1$)$. The younger women differed from the younger men with respect to body mass, height, \% FM, FFM, FFM index, EE (total, resting and activityinduced), EI, the factors cognitive restraint (F1) and disinhibition (F2) of the three-factor eating questionnaire $(P<0.01)$ and PAL $(P<0.05)$ (Table 1). The older women differed significantly from the older men with respect to body mass, height, \% FM, FFM, FFM index, $\mathrm{EE}$ (total, resting and activity-induced) and EI $(P<0 \cdot 01)$ (Table 1)

\section{Relationships}

No relationship of meal frequency with any of the variables assessed was observed in the group with a low FFM (the women).

In the group with a medium FFM (the older men) habitual meal frequency $(\mathrm{CV} 16 \cdot 3 \%)$ was positively related to resting $\mathrm{EE}(\mathrm{CV} 9.0 \%)\left(r^{2} 0.4, P<0.05\right)$ and inversely related to activity-induced EE (CV 14.6\%) $\left(r^{2} 0.3\right.$, $P<0.05$ ) (Fig. 1). Resting EE and activity-induced EE were not related. In a stepwise regression, resting $\mathrm{EE}$ explained $40 \%$ of the variation in meal frequency; adding activity-induced EE increased the explained variation to $60 \%$. Moreover, meal frequency was positively related to $\mathrm{BMI}$ in the older men $\left(r^{2} 0 \cdot 5, P<0 \cdot 01\right)$, and to body mass $\left(r^{2} 0.4, P<0.05\right)$. The relationship of habitual meal frequency with the residuals of resting EE as a function of FFM was not statistically significant $(P>0.05)$, indicating that the relationship was primarily due to FFM. Activity-induced EE was not related to FFM.

In the group with a high FFM (the younger men), habitual meal frequency (CV $31.7 \%$ ) was inversely related

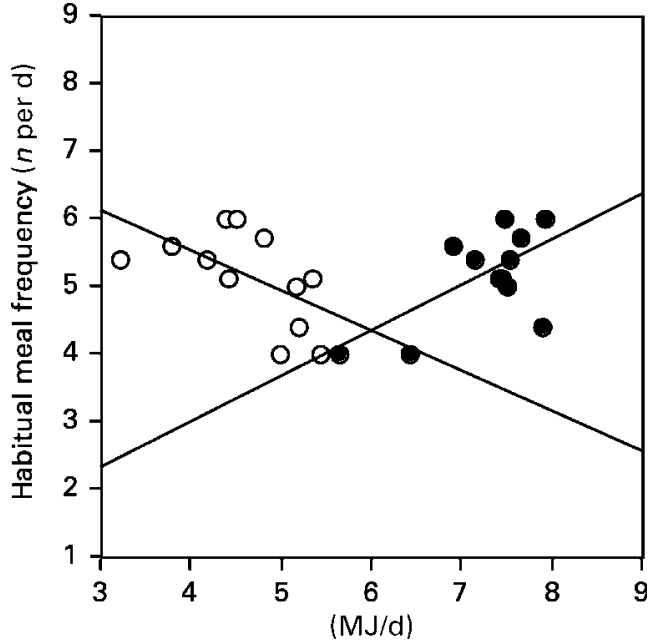

Fig. 1. Habitual meal frequency as a function of resting energy expenditure (EE) $\left(0 ; y=0.7 x+0.3, r^{2} 0.4, P<0.05\right)$ and activityinduced $\mathrm{EE}\left(0 ; y=-0.6 x+7.9, r^{2} 0.4, P<0.05\right)$ in older men ( $n$ 12). For details of subjects and procedures, see Table 1 and p. 644.

to resting $\mathrm{EE}(\mathrm{CV} 6.7 \%)\left(r^{2} 0.8, P<0.0001\right)$ and positively related to activity-induced EE (CV 4.0\%) $\left(r^{2} 0 \cdot 6\right.$, $P<0.0001$ ) (Fig. 2). Resting EE and activity-induced EE were inversely related to each other $\left(r^{2} 0.6, P<0.0001\right)$. In a stepwise regression, resting $\mathrm{EE}$ explained $85 \%$ of the variation in meal frequency; adding activity-induced EE increased the explained variation to $89 \%$. In addition, the relationship between habitual meal frequency and the residuals of resting EE as a function of FFM was statistically significant $(P=0 \cdot 03)$, indicating that this relationship was not only due to FFM, but also to resting EE independently. Activity-induced EE was not a function of FFM. Moreover, meal frequency was inversely related to BMI,

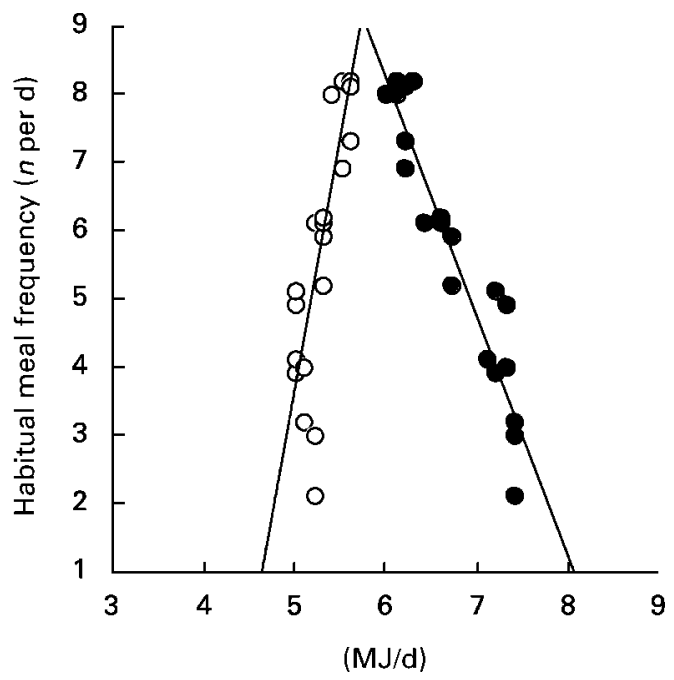

Fig. 2. Habitual meal frequency as a function of resting energy expenditure (EE) $\left(0 ; y=-3.5 x+29.3, r^{2} 0.9, P<0.0001\right)$ and activity-induced EE $\left(O ; y=7.2 x+32.5, r^{2} 0.7, P<0.0001\right)$ in younger men $(n 9)$. For details of subjects and procedures, see Table 1 and p. 644. 
body mass, height and EE in the younger men $\left(r^{2} 0 \cdot 8\right.$, $P<0.0001)$, and positively related to RQ $\left(r^{2} 0.4\right.$, $P<0.001)$, indicating a higher carbohydrate oxidation.

In the group with a high FFM (the younger men) habitual meal frequency was inversely related to EI and to \% EI from fat, and positively related to \% EI from carbohydrate. In the group with a medium FFM (the older men), there were no relationships between meal frequency and energy or macronutrient intake, or RQ (Table 1).

\section{Discussion}

Habitual meal frequency was differentially related to resting EE and activity-induced EE in subjects with a medium to high FFM, i.e. older and younger men, but not related to these variables in subjects with a low FFM (women). In the subjects with a high FFM, the relationship between habitual meal frequency and resting EE was also confirmed by the relationship between habitual meal frequency and the residuals of resting EE as a function of FFM, indicating that not only did FFM play a role in this relationship, but also resting EE independently. The latter relationship was not statistically significant in the subjects with a medium FFM, indicating that the relationship of meal frequency and resting EE depended on the relationship between resting EE and FFM. Not only did body composition differ significantly between the different FFM categories in the men, but also PAL. Here, the determinants of FFM, i.e. gender, age and physical activity, appeared as usual (Westerterp et al. 1995; Westerterp \& Elbers, 1999; Westerterp \& Goran, 1999; Westerterp \& Meijer, 2001).

In addition to differences due to body composition (such as EE) between the younger women and men, EI and the factors cognitive restraint (F1) and disinhibition (F2) from the three-factor eating questionnaire were also different. The difference in dietary restraint scores indicates that in the young men, body-weight regulation took place physiologically, but that in the young women dietary restraint appeared to be more dominant.

The difference in body composition between the older men and women explained related differences in EE and EI. The lack of a relationship in women between habitual meal frequency and EE, resting EE or activity-induced $\mathrm{EE}$, whereas in the men these relationships were present, may be explained from the difference in FFM or FFMI, and in dietary restraint. Thus, the (lack of) regulation between a factor determining EI, namely habitual meal frequency and components of $\mathrm{EE}$ (resting $\mathrm{EE}$ and activity-induced EE, body composition, i.e. FFM) may play an important role. Moreover, in younger women it is likely that the lack of such a relationship is dominated by dietary restraint, because of their higher cognitive restraint scores compared with the younger men.

In the subjects with a medium or high FFM, meal frequency was differentially related to resting $\mathrm{EE}$ and activity-induced EE. In the subjects with a medium FFM, habitual meal frequency was positively related to resting $\mathrm{EE}$ and inversely to activity-induced EE; in the subjects with a high FFM, meal frequency was inversely related to resting $\mathrm{EE}$ and positively to activity-induced $\mathrm{EE}$. In both FFM categories, activity-induced EE was not related to FFM, probably because the ranges within these categories were very small. In addition, the relationship between habitual meal frequency and resting $\mathrm{EE}$ in the subjects with a high FFM was also present independent of FFM. Here, the higher PAL in these subjects may play a role. With a higher PAL, the EE is more variable; thus, for tuning EI to EE, a high meal-frequency may be important.

To meet high energy requirements, i.e. a high resting EE (including a high EE, BMI, body mass and height) and a low activity-induced EE, subjects with a high FFM had a low meal frequency. To meet low energy requirements, consisting of a low resting EE and a high activity-induced $\mathrm{EE}$, subjects with a high FFM showed a high meal frequency. 'High' and 'low' are relative to the range of the results. A high meal frequency may tune EI to a rather variable $\mathrm{EE}$ (determined by a rather variable activity-induced EE and a high PAL) more accurately. Moreover, in active young men, eating small meals frequently may fit in with their lifestyle.

In addition to this observation of meal frequency being inversely related to resting $\mathrm{EE}$, and positively to activityinduced EE in young men, we previously showed that EI was inversely related to meal frequency. Meal frequency was supported by macronutrient intake and blood glucose dynamics, in that with a relatively high-carbohydrate and low-fat intake, frequent transient declines in blood glucose occur, causing frequent meal initiations (Westerterp-Plantenga et al. 2002). Since these meals were small high-carbohydrate meals, they caused sharp dynamic declines in blood glucose with a short inter-meal interval, thus sustaining a high meal frequency. This is supported here by the positive relationship between RQ and meal frequency in the younger men, indicating that a higher meal frequency was related to a higher carbohydrate oxidation. Thus, we propose that in younger men there may be a vicious circle of meal frequency being a function of energy metabolism variables (substrate oxidation, blood glucose dynamics, resting EE, activity-induced $\mathrm{EE}$ ), while $\mathrm{EI}$ is a function of meal frequency at the same time. In this way, meal frequency may be a tool to tune EI to EE.

To meet high energy requirements, i.e. a high resting EE (including a higher BMI and body mass) and a low activity-induced EE, subjects with a medium FFM had a high meal frequency. To meet low energy requirements, i.e. a low resting $\mathrm{EE}$ and a high activity-induced EE, subjects with a medium FFM had a low meal frequency. 'High' and 'low' are also relative to the range in which the results appear. The relationship of meal frequency to the residuals of resting EE as a function of FFM was not statistically significant. This indicates that the relationship of meal frequency with resting EE was mainly determined by FFM. The inverse relationship between meal frequency and activity-induced EE indicates that these men may exchange physical activity for eating episodes. Although there are significant relationships between meal frequency and components of $\mathrm{EE}$ in the older men, EI regulation through meal frequency seems rather weak, since a relationship with total $\mathrm{EE}$ or $\mathrm{EI}$, or with the macronutrient composition was absent. 
Thus, in subjects with a medium to high FFM, energy requirements were primarily set by resting EE, which is the largest component of EE. The men used meal frequency in different ways to meet these requirements: when the requirements (i.e. resting EE) were high, younger men (high FFM) consumed fewer meals and the older men (medium FFM) consumed more meals; both strategies resulted in a higher EI. In addition, time management was different between the older and the younger men. A lower EI was achieved in the younger men by more meals and a more active lifestyle at the same time, while in the older men this was achieved by fewer meals, sparing time for a more active lifestyle; both strategies showed time interference.

The differences in slopes between the Figs 1 and 2 are due to the CV being smaller for resting EE and activityinduced $\mathrm{EE}$ in the young men, but larger for habitual meal frequency. This indicates a flexibility in meal frequency, and hence the possibility of more accurate EI regulation in the young men. In the older men, support of EI regulation through meal frequency was weaker: the $\mathrm{CV}$ for meal frequency was smaller, indicating less flexibility, but for resting EE and activity-induced EE the CV was larger, indicating a wider range in the magnitude of the components of EE. Therefore, observations in the literature with respect to a greater appetite control and a lower BMI associated with a higher habitual meal frequency (Fabry et al. 1964, 1966; Hejda \& Fabry, 1964; Metzner et al. 1977; Charzewska et al. 1981; Edelstein et al. 1992; Speechly \& Buffenstein, 1999; Speechly et al. 1999) may be mainly caused by the stronger effects shown in young men included in those studies, but do not hold for the older men.

Taken together, since in subjects with a high FFM (young men) accuracy of regulation of EI was shown to be a function of meal frequency (Westerterp-Plantenga et al. 2002) and meal frequency a function of energy metabolism variables, we suggest that in these subjects meal frequency might be a tool for tuning EI to EE.

The lack of a relationship between a factor in EI, namely habitual meal frequency, and components of EE, namely resting $\mathrm{EE}$ and activity-induced $\mathrm{EE}$, in subjects with a low FFM (women) is suggested to be related to the lower FFM. In the case of dietary restraint, tuning EI to EE may be a matter of body-weight management rather than of body-weight regulation.

We conclude that in subjects showing a physiological body-weight regulation, indicated by a low score on dietary restraint, FFM and PAL may be important factors in tuning EI to EE, using meal frequency.

\section{References}

Bellisle F, McDevitt R \& Prentice AM (1997) Meal frequency and energy balance. Br J Nutr 77, S57-S70.

Charzewska J, Kulesza W, Brzezinska J \& Chwojnowska Z (1981) Relationship between obesity or overweight development and the frequency of meals, their distribution during the day and consumption of atherogenic food products. Zywienie Czlowieka $\mathbf{8}, 217-227$.
Dalosso H, Murgatroyd PR \& James WPT (1982) Feeding frequency and energy balance in adult males. Hum Nut Clin Nutr 36C, 25-39.

Dreon DM, Frey-Hewitt B, Ellsworth N, Williams PT, Terry EB \& Wood PD (1988) Dietary fat: carbohydrate ratio and obesity in middle aged men. Am J Clin Nutr 47, 995-1000.

Drummond SE, Crombie NE, Cursiter MC \& Kirk TR (1998) Evidence that eating frequency is inversely related to body weight status in male, but not female, non-obese adults reporting valid dietary intakes. Int J Obes Relat Metab Disord 22, $105-112$.

Edelstein SL, Barrett-Connor EL, Wingard DL \& Cohn BA (1992) Increased meal frequency associated with decreased cholesterol concentrations; Ranco Bernardo CA, 1984-1987. Am J Clin Nutr 55, 664-669.

Fabry P, Fodor J, Hejl Z, Braun T \& Zvolankova K (1964) The frequency of meals: its relation to overweight, hypercholesterolaemia, and decreased glucose tolerance. Lancet ii, 614-615.

Fabry P, Hejda S, Cerna K, Osoncova K, Pechor J \& Zvolankova K (1966) Effect of meal frequency in schoolchildren: changes in weight-height proportion and skinfold thickness. Am J Clin Nutr 18, 358-361.

Goris AHC, Meijer EP, Kester A \& Westerterp KR (2001) The use of a tri-axial accelerometer for the validity of reported food intake. Am J Clin Nutr 73, 549-553.

Goris AHC \& Westerterp KR (2000) Improved reporting of habitual food intake after confrontation with earlier results on food reporting. Br J Nutr 83, 363-369.

Goris AHC, Westerterp-Plantenga MS \& Westerterp KR (2000) Undereating and underrecording of habitual food intake in obese men: selective underreporting of fat intake. Am J Clin Nutr 71, 130-134.

Hejda S \& Fabry P (1964) Frequency of food intake in relation to some parameters of the nutritional status. Nutr Dieta 6, $216-221$.

Kant AK (1995) Frequency of eating occasions and weight change in NHANES I Epidemiologic Follow-up Study. Int $J$ Obes Relat Metab Disord 19, 468-474.

Melanson KJ, Westerterp-Plantenga MS, Campfield LA \& Saris WHM (1999) Short term regulation of food intake in humans. In Regulation of Food Intake and Energy Expenditure, pp. 37-58 [MS Westerterp-Plantenga, AB Steffens and A Tremblay, editors]. Milan: Edra, Medical Publishing \& New Media.

Metzner HL, Lamphiear DE, Wheler NC \& Larkin FA (1977) The relationship between frequency of eating and adiposity in adult men and women in the Tecumseh Community Health Study. Am J Clin Nutr 30, 712-715.

Speechly DP \& Buffenstein R (1999) Greater appetite control associated with an increased frequency of eating in lean males. Appetite 33, 285-297.

Speechly DP, Rogers GG \& Buffenstein R (1999) Acute appetite reduction associated with an increased frequency of eating in obese males. Int J Obes Relat Metab Disord 23, 1151-1159.

Stichting Nederlands Voedingsstoffen Bestand (1993) Voorlichtingsbureau voor de Voeding (Information Office for Nutrition). The Hague: Information Office for Nutrition.

Stunkard AJ \& Messick S (1985) The Three Factor Eating Questionnaire to measure dietary restraint, disinhibition and hunger. Psychosom Res 29, 71-83.

Summerbell CD, Moody RC, Shanks J, Stock MJ \& Geissler C (1996) Relationship between feeding pattern and body mass index in 220 free-living people in four age groups. Eur $J$ Clin Nutr 50, 513-519.

Verboeket-van de Venne WPHG \& Westerterp KR (1991) Influence of the feeding frequency on nutrient utilisation 
in man: consequences for energy metabolism. Eur J Clin Nutr 45, 161-169.

Verboeket-van de Venne WPHG, Westerterp KR \& Kester ADM (1993a) Frequency of feeding, weight reduction and energy metabolism. Int J Obes Relat Metab Disord 17, 31-36.

Verboeket-van de Venne WPHG \& Westerterp KR (1993b) Effect of the pattern of food intake on human energy metabolism. Br J Nutr 70, 103-115.

Westerterp KR \& Elbers JHM (1999) Gender differences, energy balance, and effects of sex steroid hormones on circulating leptin levels. In Regulation of Food Intake and Energy Expenditure, pp. 305-324 [MS Westerterp-Plantenga, AB Steffens and A Tremblay, editors]. Milan: Edra, Medical Publishing \& New Media.

Westerterp KR \& Goran MI (1999) Age and energy balance. In Regulation of Food Intake and Energy Expenditure, pp. 325-348 [MS Westerterp-Plantenga, AB Steffens and A Tremblay, editors]. Milan: Edra, Medical Publishing \& New Media.

Westerterp KR \& Meijer E (2001) Physical activity and parameters of aging: a physiological perspective. J Gerontol 56A, 7-12.
Westerterp KR, Wouters L \& van Marken Lichtenbelt W (1995) The Maastricht protocol for the measurement of body composition and energy expenditure with labeled water. Obes Res 3, 49-57.

Westerterp-Plantenga MS, Kovacs EMR \& Melanson KJ (2002) Habitual meal frequency and EI regulation in partially temporally isolated men. Int J Obes Relat Metab Disord 26, $102-110$.

Westerterp-Plantenga MS, Rolland V, Wilson SAJ \& Westerterp KR (1999) Satiety related to $24 \mathrm{~h}$ diet-induced thermogenesis during high protein/carbohydrate vs high fat diets measured in a respiration chamber. Eur J Clin Nutr 53, 495-502.

Westerterp-Plantenga MS, Wijckmans-Duysens NEG \& ten Hoor F (1994) Food intake in the daily environment after energyreduced lunch related to habitual meal frequency. Appetite 22, 173-182.

Wolfram G, Kirchbegner M, Mueller HL \& Hollomey S (1987) Thermogenese des Menschen bei unterschiedlicher Mahlzeithaeufigkeit (Thermogenesis in human subjects with differing meal frequencies). Ann Nutr Metab 31, 88-97. 